\title{
A Coasian Solution to Problems of Initial Acquisitions
}

\author{
MATS EKMAN \\ Hanken School of Economics
}

\begin{abstract}
This article extends the Coase Conjecture to ethical issues of initial acquisitions of property rights. The Coase Conjecture complements the Lockean labour-mixing criterion to limit the boundaries of morally legitimate initial acquisitions of unowned property; whenever the Coase Conjecture applies, the Lockean Proviso that there be "enough and as good" left is automatically satisfied. This holds provided that, when a claim is made, the marginal willingness to pay for the last portion of it is zero (infra-marginally, willingness to pay may be arbitrarily high). Thus, the market price of the claim is zero, except for the part of it that the claimant inhabits or improves. "Excessive" claims therefore come to have a zero market price, so anyone may take possession of them, by purchase or theft. In either case they must compensate the original claimant by a zero amount. It follows that non-claimants do not lose by putatively "excessive" grabs by claimants. This article argues that any initial claims are just under these circumstances.
\end{abstract}

Keywords: property rights, initial acquisition, labour-mixing criterion

JEL Classification: D60, P14

\section{INTRODUCTION}

Suppose that you are the first person to come upon a vast area of land that no one has claimed yet, such as an undiscovered island or planet. You announce your ownership of the land in its entirety. If you were then to sell the land, whole or in individual parcels of whatever sizes, and there were just enough interested buyers to purchase and settle exactly all of what you claim to be your newly-acquired possession, how much money would you make? A perhaps surprising answer is that you would make no money at all. This answer holds in general for property

AUTHOR'S NotE: Special thanks to Willem van der Deijl and two anonymous referees for helpful comments and suggestions. The usual disclaimer applies. The support of the Society of Swedish Literature in Finland is also gratefully acknowledged. 
of durability, and depends neither on the legal status of your property right, nor on any sudden fit of generosity on your part; even if everyone paid the highest price asked, you still would not make any money.

The explanation for this outcome is due to Ronald Coase (1972) and is commonly known as the Coase Conjecture. The conjecture states that, given that all the land will be sold, the price of the final unit sold (be it an acre or a square inch) determines the price of all units. More generally, when the Coase Conjecture applies, price equals marginal cost, since otherwise the monopolist always has an incentive to lower his price.

In the acquired land example, because demand is great enough to settle exactly the claimed area but no more, the buyer who is least eager to settle, is indifferent between buying and abstaining. Hence, he has a willingness to pay of zero. This is the willingness to pay of the buyer of the last plot of land. If it was any lower, he would no longer settle, and the resultant lower demand would not alter the price (the claimant would have to pay people to take the land, which is worse for him than holding on to it). If it was any higher there ought to be more willing settlers, which by assumption there are not.

Under these demand conditions, a price equal to marginal cost will be zero, because cost is the value of the best-foregone alternative. So, if the cost of holding on to a durable good is to sell it, the marginal cost is equal to the price a purchaser is willing to pay for an additional unit of the durable good (the marginal willingness to pay for the last unit sold). Such demand conditions are more likely to apply in circumstances when initial acquisitions are made, that is when there are relatively plentiful durables compared to interested potential claimants, which seems a useful characterization of conditions around the time of the dawn of man.

As Coase explains in his seminal article (1972), the initial acquirer could have restricted himself to selling only half of the land (say), in order for the reduced supply to fetch him a higher price per unit sold. But once this is done, it would make sense to keep selling, which would cause a reduction in price. This holds at every price, as long as the price is above marginal cost (in this case above zero): the initial acquirer gains no utility from the mere possession of land, and purchasers are patient and forward-looking enough to realize that monopoly prices will eventually fall. To wit, the initial acquirer is in competition with his own past actions as he always wants to keep selling off his holdings, but the 
more he sells, the more units crowd the market (this is why the Coase Conjecture only applies to durables).

Much of the moral philosophy of property rights is concerned with the question of how they can be acquired in the first place. This question pertains to the legitimacy of any private property, since transfers of property must eventually trace back to unowned things. The Lockean labour-mixing criterion, which states that a property right is rightfully acquired by whomever is first to mix his or her labour with it (Locke 1967), is often thought rather vague with respect to the precise quantity it entitles the labour-mixer, giving rise to the so-called boundary problem. Simmons puts the well-known criticism thusly: "It is not obvious that labor can ground a clear right to anything if it is not possible to specify the boundaries of what is acquired" (1992 268, original emphasis).

The Coase conjecture eliminates the boundary problem. Under the above conditions, if an initial acquirer claims more land than he can use, the market price of the unused land will be zero. Thus, anyone can settle the unused land, the initial settler's claim notwithstanding; whether by purchase or theft, compensation is zero. Moreover, what counts as labour is defined as whatever action increases the value of the acquisition. This definition of labour precisely delimits the extensive boundaries of rightful initial claims (area), while satisfying Locke's labour-mixing criterion. Other apparent problems with property rights, concerning their intensive boundaries (precisely which use rights have been acquired), also vanish when the Coase Conjecture is applied to them, as this article illustrates.

The right to aspects of a resource, such as the exclusive right to till soil but not the exclusive right to trespass on it, may be referred to as the intensive boundaries of property rights. ${ }^{1}$ If the initial acquirer has raised the price of land from zero to something positive purely by cultivating it, his sale of the land to someone else is really only a sale of the tilling rights. The rights to other aspects of the land, such as trespassing, conflict with tilling rights if the market prices of tilling and trespassing rights are affected, as shall be discussed at greater length in Section III. Henceforth, this article will treat use rights as synonymous

\footnotetext{
${ }^{1}$ Alchian and Demsetz provide a concise explanation of rights to resources as properly thought of as bundles of rights: "One party may own the right to till the land, while another, perhaps the state, may own an easement to traverse or otherwise use the land for specific purposes. It is not the resource itself which is owned; it is a bundle, or a portion, of rights to use a resource that is owned" (1973, 17, original emphasis).
} 
with property rights, and uses the label Principle of Positive Price (PPP for short), to refer to the criterion that a rightful initial acquisition is determined by a positive market price.

Apart from the boundary problem, the main critique of the labourmixing criterion concerns the deprivation of possibilities for nonacquirers to claim unowned property once it has been mixed with someone else's labour (see, for instance, Kymlicka 1990, 117, passim). By the Lockean Proviso, non-acquirers must not be made worse off when claimants privatize unclaimed property, though this condition is found to be objectionable by many. Perhaps most fundamentally, Kantianism seems to require unanimity for original claims to be just, since unilateral appropriations would otherwise impose obligations upon others that they would not otherwise have (Kant 1996, 254; also Pufendorf 2005, Book IV, 322).

Relatedly, Cohen (1995) argues that the Proviso has virtually no domain in realistic cases, and asks why initial acquisitions are not considered "theft of what rightly should (have continued to) be held in common?" (73). His question indicates a conflict with the stress entitlement theorists otherwise put on individual autonomy when access to common property has been restricted $(73,80)$. Similarly, Waldron $(1988,280)$ objects that once a fairer distributive mechanism is available than that of Lockean original appropriation, the holdings of initial acquirers lose their legitimacy.

By the Coase Conjecture, the Lockean Proviso is satisfied whenever non-acquirers face a zero price for the property right in question (what distributive mechanism could be fairer?), and is violated for a positive price. Ceteris paribus, undifferentiated property will have a lower marginal willingness to pay at any given quantity than will differentiated property. This latter case obtains when $X$ picks up a pretty rock wanted by $\mathrm{Y}$. Now $\mathrm{Y}$ is deprived of the opportunity to pick up this particular pretty rock for free. The former case obtains when $\mathrm{X}$ and $\mathrm{Y}$ are both looking for undifferentiated property such as fertile land or rocks in general.

This article therefore covers the boundary problem and the part of the deprivation argument concerned with undifferentiated property. ${ }^{2}$ By

\footnotetext{
2 Treatments of initial acquisitions of differentiated property tend to find it questionable whether non-acquirers' rights are violated since the acquired property was not theirs (see, for instance, Feser 2005). Additionally, there is the argument that, if currently propertyless individuals were given all the pertinent information on how the world would have evolved in the absence of private property rights, it is unlikely
} 
presenting a way in which unowned use rights may be privatized, the present argument may illuminate Lockean labour-mixing (a zero market price implies no labour-mixing). Additionally, since new use rights may continue to be claimed, such as for mineral rights on other planets or for new uses on Earth, this article will have practical importance for future initial acquisitions (a zero market price implies non-acquirers have not been deprived of opportunities).

Throughout this article, it will be assumed that initial claims to property are claims to previously unowned property, rather than to property that was initially commonly owned. This choice of focus is more fruitful because it is more challenging: if something belongs equally to all, then one could show one's altruism by renouncing ownership of one's share, thereby increasing the shares of remaining owners, or one could buy out remaining owners. These possibilities illustrate how common ownership is only a special case of private ownership. Under the view that everyone shares equally in the ownership of everything, the problem of how ownership is acquired is assumed away.

The remainder of this article is structured as follows: Section II is the basis of this article. It outlines the Coase Conjecture and argues for its plausibility in delimiting the extent to which labour-mixing entitles one to ownership. It also discusses potential counterarguments and highlights sensitivities to important assumptions underlying the Coase Conjecture. Section III revisits some other problems with moral systems based upon property rights and finds that many of them, especially problems of externalities, lessen in intensity when the zero-price criterion is applied to particular use rights. In other words, Section II focuses on the extensive limits on ownership and Section III on the intensive ones. Section IV concludes.

that they would choose to do away with private property, since doing so would give rise to the so-called commons problem, in which there are no incentives to improve upon anything, because others have the same right to the improvement as the improver. 


\section{The CoAse Conjecture ${ }^{3}$}

Because an initial acquirer has an incentive at every margin to keep selling his uncreated acquisition and the increasing supply competes with previously sold land, a positive price for it is impossible under the conditions discussed in the introduction. In an initial situation with no claimed durable property, a person might claim all of Earth. Unless the quantity of land demanded at a price of zero exceeds the land area of the planet, the claimant will not make a penny by selling his holdings. If, instead, he claimed ownership of some fraction of the planet, unclaimed land would be left to compete with his claim for buyer-claimants, dragging down the price to zero again. What causes this outcome is the durable characteristic of initially acquirable property; given that the entire quantity will be supplied, the market price reflects that amount.

The defining characteristic of a monopolized market is that output is lower (or at least no higher), and price is higher (or at least no lower), than they are under competition. It immediately follows that one person's monopolization of some resource maximizes potential harm to others, since in no non-monopolistic situation can output be lower or price higher. Since prices measure this damage in the form of a comparative loss to non-claimants (due to the fact that someone else happened to announce ownership first) the application of the Coase Conjecture to original appropriations is useful in its ability to measure such losses, a quantification that is made more interesting by the zeroprice outcome.

Figure 1 illustrates the basic price theory behind the Coase Conjecture. $\mathrm{Q}^{\text {TOTAL }}$ denotes the total amount of the property in question and DD shows the demand schedule with marginal willingness to pay for each quantity in DD. Where DD and the horizontal axis intersect, marginal willingness to pay is zero. In panel (a), $\mathrm{Q}^{\mathrm{TOTAL}}$ is above the point where marginal willingness to pay is zero, which, by the logic presented in the preceding discussion, indicates that all of the acquisition would sell for a zero price. In such a scenario, it is hard to see what a nonacquirer's complaint would look like.

\footnotetext{
${ }^{3}$ The convention of calling this result a "conjecture" is due to its initial controversy among economists and masks its importance. The result has indeed been affirmed by numerous other economists. See, for instance, Gul et al. (1986). Certain refinements that nevertheless do not upset the main result are found in Bulow (1982) and in Tirole (1988). Readers unfamiliar with the Coase Conjecture should take care not to confuse it with the Coase Theorem (Coase, 1960).
} 
The Coase Conjecture says that sales will be made at marginal cost, so this point illustrates that under conditions such as those of panel (a), marginal cost equals zero. Since cost is the value of the best alternative not used, it follows that possessing a durable thing foregoes the revenue generated by its sale. Consequently, marginal cost is equal to the price a purchaser is willing to pay for an additional unit of the durable thing, which is zero in the diagram on the left. In panel (b), by contrast, the total quantity is less than the amount that exhausts positive aggregate willingness to pay, which causes the boundary problem to reappear and necessitates some form of competitive allocation (whether or not one individual announces ownership of the amount $\mathrm{Q}^{\text {TOTAL}}$ ).

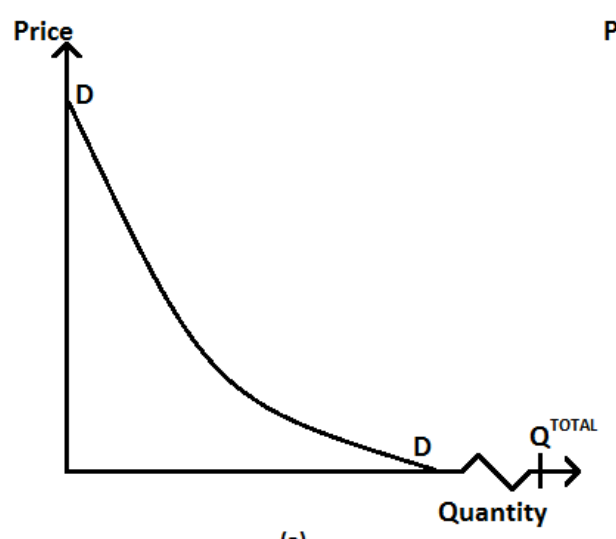

(a)

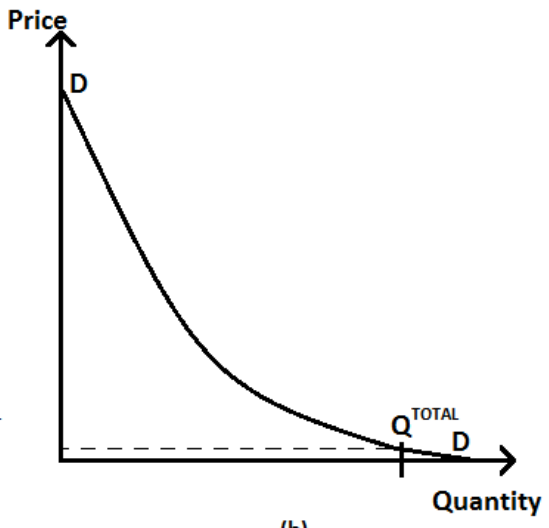

(b)

Figure 1

The usefulness of the PPP in determining rightful initial acquisitions may be illustrated by a reply to Nozick $(1974,175)$, who inquires whether his pouring a can of tomato juice into the sea, so that the juice's molecules mingled "evenly throughout the sea", would make him the rightful owner of the sea (see, for instance, Sanders 1987). Under the PPP, Nozick may be said to own the (hitherto unclaimed parts of the) sea, but the resultant market price of his holdings would make his proprietorship irrelevant. If someone else claims some small part of Nozick's holdings, Nozick can take legal action, but what restitution can he demand? The market price is zero. If people were willing to pay somewhat more for a part of the sea due to the presence of tomato juice molecules in it, that could cause the market price to rise above zero (and then Nozick would have improved the sea), but given the small amount of tomato juice, even the presence of a million cans of it would hardly cause the price to increase. 
Later in the same passage, Nozick also asks why the labour-mixing requirement should not apply only when the holding increases in value, or only to the added value. According to the PPP, these two criteria come to the same thing, because with an initial sale price of zero the addition of, say, a house on land is both the increase and the full value of the

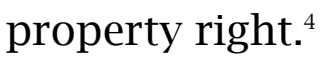

Sensitivity to Assumptions: The assumption of durability is important, because the Coase Conjecture applies only to durable resources; if an initial acquirer of something non-durable were to make "excess" claims, his past sales would not compete with his current supply, which means that he can much more easily charge a positive price. But the problem of initial acquisition in moral philosophy is essentially limited to things that are not created, or at least not created in significant part. This is indicated by the fact that the most common example philosophers use when discussing initial acquisitions is land; it is further supported by the fact that unappropriated non-durables will soon perish, which ensures that acquisitions do not deprive nonacquirers.

There are sensitivities to note other than eliminating future possibilities to stake claims to unowned property. Clearly, if the quantity demanded exceeded total supply, the last buyer would not have a willingness to pay of zero and the initial acquirer would therefore receive a strictly positive price for each unit of land sold. Under these conditions, it would be profitable to merely announce ownership of Mars, say, or of anything presently unowned. Although the resultant allocation by valuation (willingness to pay) may be relatively less objectionable than other allocation mechanisms, this would be orthogonal to the case of a zero market price.

\footnotetext{
${ }^{4}$ Conversely, one could reduce the value of one's claim so that the last unit sold would fetch a negative price. In such cases, whether one is liable to compensate other acquirers is a trickier issue because one could always abandon one's property in case of such retrogression. The situation is as if one went into unowned land and reduced its quality. At the time of one's action, there is evidently no one to claim compensation, but eventually someone may claim the negatively priced land (presumably because he has an idea that can turn it into land fetching a positive price). Should this claimant be compensated by the destroyer because of the extra efforts he had to exert? Someone else may have claimed the land before him if it were not negatively impacted by the destroyer's actions. It is possible that retrogression of initially acquired property makes the destroyer duty-bound to make amends. However, for the purposes of this article, it suffices that reducing the quality of an unowned resource does not make one a rightful property-holder.
} 
Notice, however, that low demand is the norm whenever initial acquisitions are likely to take place. It is only when uncreated things can be connected to markets that they acquire commercial value. Barring serendipitous cases, such new connections are necessarily discovered by persons of exceptional ability, who perceive possibilities that no one else sees. Otherwise the property would not have been left unclaimed. Much American land was settled only when advances in transportation made it profitable for agriculture, pasturing, or other uses (see the various discussions of land in North et al. 1983). Before connections to markets had been established, the land was hardly useful to anyone and it was not certain that it ever would be. Indeed, those who speculated on such land made highly variable returns, losing or gaining fortunes (as documented in Bogue and Bogue 1957).

Counterarguments from Industrial Organization: Monopolists committed not to lower their prices will trivially succeed at charging more than marginal cost for their durable products. However, while the textbook case in which lower profits temper temptations to increase sales by supplying more than the quantity at which marginal cost equals marginal revenue for perishable products, buyers know that in the next "period" (that is, when the monopolist adjusts his price), the present period's supply will compete with whatever else he sells, forcing down the price. ${ }^{5}$

The field of Industrial Organization has also produced other qualifications for the Coase Conjecture. For example, commitment may be achieved through the destruction of the monopolist's factory, but since the present article deals with uncreated goods, this commitment device does not apply. An alternative method is to promise to repurchase whatever one sells at a given price, but doing so has the unhappy consequence of leaving the monopolist overstocked and consequently incentivized to give secret discounts to new consumers, a possibility which renders his commitment less credible.

A well-known result suggests that a monopolist can avoid marginalcost pricing by leasing his product rather than selling it. However, leasing has problems of its own. When a monopolist recognizes his clients, he will over time infer their willingness to pay. This reduces demand as future-orientated high-valuation consumers can mimic low-

\footnotetext{
${ }^{5}$ Many textbooks state the technical condition for the Coase Conjecture to apply as these periods being of very short duration; that is, when monopolists cannot commit not to lower their prices in the next instant-see, for instance, Tirole (1988, 82-83).
} 
valuation ones, forcing the monopolist's price to go down. Hart and Tirole (1988) show that, absent anonymity, leasing will tend to yield lower profits than do sales. Additionally, issues such as moral hazard (lessee's lack of care) and adverse selection (lessors attracting careless lessees) reduce the attractiveness of leasing independently of the problems raised by Hart and Tirole.

Another technical assumption underlying the Coase Conjecture is that the monopolist's pricing horizon must be infinite. While this assumption may sound demanding, it is only made to ensure that there is no known last period, as that would eliminate possibilities for further intertemporal competition. This assumption is also more natural when considered in light of a monopolist's concern for his children (who in turn care for their children, and so on).

The Coase Conjecture has sparked an enormous amount of research in Industrial Organization and the precise domain of the Coase Conjecture is still not clear. This means that its applicability to ethical issues of initial acquisitions may depend on highly situation-specific circumstances, which is always inferior to results that will obtain under any circumstances. At any rate, one may safely say that the Lockean Proviso will be satisfied whenever the Coase Conjecture can be applied.

Counterargument from Links to Adjacent Property: Could one not hold the right to a certain kind of view from a rightfully acquired claim? If so, one would have the right to limit the appearance of adjacent property, including the right to prohibit new structures from being erected. However, the part of the resource to which a claimant can justly hold a property right extends only so far as the aspects of it that have increased in market value. A view over surrounding areas has experienced no such change and therefore, by the PPP, cannot be claimed.

On the other hand, views from adjacent land may have increased in value if the structure the initial acquirer erected on his claim raises the market price of viewing it. In this way, the initial acquirer would come to rightfully possess the views from adjacent land, but not the view from the land he acquired. If three points are located on a line so that an initial acquirer holds the leftmost point $\mathrm{A}$, could he prevent an acquirer of the middle point B to block the view of his structure from the rightmost point $\mathrm{C}$ ? In other words, may the first acquirer in an area legitimately prevent others from settling in the vicinity, if doing so impairs the view of the first acquirer's structure from somewhere? 
Notice that this takes the reasoning back to the original monopolist's pricing problem analysed by Coase, for a view is certainly a durable consumption good, and so any positive price that the first acquirer asks of new settlers to compensate the alteration of his view rights will be too high as the quantity sold at that price will be lower than the quantity he could sell at a lower price (assuming, again, that all the surrounding land could not be sold until the price dropped to zero). He is tempted to keep lowering his price and under the conditions discussed previously in this article, the first acquirer will charge a zero price.

Counterargument from Conflict Settlements: So far, it has been assumed that conflicts over property rights to durable resources with a market price of zero are settled by letting the intruder take possession of the property right, against compensation to the initial acquirer by the amount of the market price. If instead the initial acquirer could turn down this settlement, or if a court ordered that the intruder leave, the problem of excessive initial acquisitions would reappear (see, for instance, Calabresi and Melamed 1972).

A related point is that mere ownership could yield utility, such as when an original acquirer simply enjoys being in possession of vast tracts of land. One argument against the likelihood of situations like these is that the intruder could come again and again (or other intruders could come), eventually exhausting the initial acquirer's patience so that the property right is ceded to the intruder against zero compensation. Knowing this, the initial acquirer might as well acquiesce to ceding his property.

Summing up: In light of this discussion, initial claims beyond those that the claimant inhabits, works, or can hire people to work for him, seem practically irrelevant. Many details may alter the applicability of the Coase Conjecture, but its zero-price implication serves as a useful existence theorem for rightful initial acquisitions and highlights several situations where appropriations are clearly delimited in the same way. When defining the rightful extent of initial acquisitions, the Coase Conjecture can prove quite useful.

Applied to the moral permissibility of initial acquisitions, the power of the Coase Conjecture is conditional on zero prices. Since one cannot be certain that the conditions for zero pricing apply, this article merely argues for their probability. Nonetheless, the idea of pricing an acquisition and the prevalence-at least under the highlighted circumstances-of zero prices, appears to agree with common sense 
ethical views: Farmers of virgin soil acquire the plots they plough, but not parts of adjacent plots; fishermen may gain a right to the area where they throw their nets, but not to waters several knots away; and space travellers acquire rights to the parcels of previously uninhabited planets they settle, but not to the whole planet.

\section{New Solutions to Old Problems of Property Rights}

This section discusses some of the classic problems with property rights that concern mainly their intensive extent (that is, the particular uses of a resource which are owned), and how the PPP may illuminate such issues. By the definition of property rights employed in this article, they refer to uses of resources rather than to the resources themselves, so new property rights may be claimed on existing resources as long as those uses do not interfere with the market prices of the existing use rights. For instance, if B claims an easement after A has claimed a piece of land, B's claim is illegitimate if honouring it would reduce the market price of A's use right to the land, and legitimate otherwise.

The easement may consist in the transmission of radio waves across a piece of land used for agriculture, or a right of passage. It can in principle be qualified so that $\mathrm{B}$ has the right to (say) trespass a certain number of times per day. If someone else, C, wants the same easement, he can obtain it, provided-again-that it does not reduce the value of A's use right or B's easement. In this way, the PPP determines the intensive boundaries of property rights. If a further easement reduces the market price of extant easements, or of A's use rights, those easements are illegitimate. ${ }^{6}$

The introduction mentions how original appropriations have been criticized for enabling unilateral impositions of duties by the initial acquirer on everybody else (Kant 1996; Pufendorf 2005). Since property rights refer to rights to use resources in certain ways rather than to the resources themselves, the PPP applies even in a world in which all resources have some use that has been appropriated. If the actual resources were owned, it would be problematic to acquire new property rights on a finite planet, but since human ingenuity could prove capable of finding limitless new uses, initial appropriations may go on forever.

\footnotetext{
${ }^{6}$ Of course, if A rightfully holds an easement and B wanted it strongly enough, there is no stopping $B$ from buying it. If so, the easement would go to the person valuing it most intensely. This outcome would be efficient in the sense of maximizing well-being as captured by willingness to pay, and happens to be another result due to Ronald Coase known as the Coase Theorem (Coase, 1960).
} 
Moral objections to initial appropriations are much harder to make if acquirers do not deprive non-acquirers of anything. True, original acquirers do unilaterally impose duties on others by claiming some use right, but when the market price of the use right is zero, the weight of this duty would seem to be zero as well. A zero price implies that "enough and as good" of undifferentiated use rights remain.

A few examples may usefully illustrate how prices and initial acquisitions work at the intensive margin. Sally's watching TV near a window in her house causes the emission of photons to her neighbour Bob's property. Bob demands that Sally cease the unwelcome intrusion. Sally might say that she only emits a few photons that are hardly noticeable, but Bob insists that it is for him to know whether her actions inflict harm upon him. ${ }^{7}$ Airplanes flying over one's house typically interfere in the same minute way with one's property value ('minute', provided they maintain a sufficient altitude), and offer an additional example, as do the radio waves.

The issue here is whether the easement to transmit the number of photons coming from Sally's TV set (or noise from airplanes, or radio waves) would reduce the market price of Bob's existing use rights to his home. If the answer is no, then Bob has not in fact acquired the disputed use rights; trespass rights for (a sufficiently low number of) photons remain unclaimed. The impact of an easement on the market price of the other use right determines whether there has been a violation.

This criterion may seem unfair on highly original persons who believe themselves to have made rightful claims, but who will not be listened to. However, in a world with a ten-digit population, all of whom are potentially in the market for some odd property right, one would have to be highly original indeed to suffer from the PPP. Moreover, even if one is that original, the option remains open to purchase the disliked use right.

The present argument is distinct from the claims that, if no loss is experienced, no harm has been done. Such normative ethical theories might justify the (prophylactic) raping of unconscious persons or the usage of cars at times when their rightful owners are known never to use them (provided their condition was completely restored afterwards). It might seem that price consequences are absent because so are experiences of loss. But this is a mistake. Price consequences are present

\footnotetext{
${ }^{7}$ David Friedman cites this scenario as an argument against relying on property rights for moral reasoning (1989, chap. 41).
} 
because prices do not come from changed personal experiences but from market expectations of experiences. For instance, market participants are likely willing to pay more for a car that they can use at any time. The same argument, mutatis mutandis, may be applied to putatively insignificant amounts of pollution and other external effects. Supposing only a limited number of pollutants may legitimately traverse on someone's property, the property-holder can demand that polluters reduce their emissions once this threshold is hit. As before, the threshold would be at the point where the price of an emission right turns positive, which is likely to vary with affluence, geographical features (such as the smog-prone Los Angeles Basin or San Fernando Valley), and so on.

Low-probability disasters that harm third parties without their consent, like airplanes crashing on somebody's property, may also be allowed as easements. At-risk individuals have a right to ban air travel if they have claimed that part of the bundle of rights attached to their property that governs subjection to harmful events of a miniscule probability. And as before, the test of the rightfulness of this claim is whether it can be sold for a positive price in the market, the PPP.

If the low-probability disasters affect human life rather than inanimate property, a similar case may be made. On this view, one owns oneself, but one may not have claimed every aspect of oneself. Rights not to be killed with certainty or with non-miniscule probabilities would certainly be sold for positive prices, for others' holding such rights would enable extraction of a great deal of resources from the person to whom the rights apply. But rights not to be killed by certain freak accidents of vanishingly small probability (such as satellites crashing on one's head) quite possibly would fail to fetch a positive price (in which case launchers of satellites do not have to ask permission from all of us). Whether the right not to be put at risk by such events of miniscule probabilities would fetch a positive price or not is ultimately an empirical question. One indicator for the rightfulness of claims not to be the victim of freak accidents is a positive (minus administrative costs) actuarially-fair insurance premium.

\section{CONCLUSION}

The Coase Conjecture was first published in 1972 and while its precise domain is still not clear, this article attempts to show how the Lockean Proviso that "enough and as good" unowned property remains, will tend 
to be satisfied when the Coase Conjecture does apply. This may help to defuse certain points of contention in moral philosophy regarding the justice of initial acquisitions in general.

An important problem with the Lockean labour-mixing criterion is its vagueness vis-à-vis what constitutes labour and precisely what it means to mix labour with property. The Coase Conjecture sharpens the labour-mixing criterion by examining its consequences for price. In particular, a positive price determines whether a claim is legitimate. A zero market price means that new claimants effectively cannot be turned away, while non-claimants have no reason to complain that the commons disappear, since they, too, could be zero-price initial acquirers.

The main contribution to the moral philosophy of property rights by the present article is therefore two-pronged. Firstly, the boundary problem of determining the extent of a particular use right is in principle solved by examining the market price of each portion of the claim. Where positive, the claim is legitimate; where zero, it is not. Secondly, initial acquisitions are delimited intensively by a similar examination of market prices to sundry uses of a resource, as in the potential for tilling, passage, and radio transmission rights belonging to different people even though their rights refer to the same physical location.

\section{REFERENCES}

Alchian, Armen, and Harold Demsetz. 1973. "The Property Right Paradigm.” The Journal of Economic History 33 (1): 16-27.

Bogue, Allan, and Maragaret Bogue. 1957. “`Profits’ and the Frontier Land Speculator.” Journal of Economic History 17 (1): 1-24.

Bulow, Jeremy. 1982. “Durable-Goods Monopolists.” Journal of Political Economy 90 (2): 314-332.

Calabresi, Guido, and A. Douglas Melamed. 1972. "Property Rules, Liability Rules, and Inalienability: One View of the Cathedral." Harvard Law Review 85 (6): 1089-1128.

Coase, Ronald. 1960. "The Problem of Social Cost." Journal of Law and Economics 3 (1): $1-44$.

Coase, Ronald. 1972. "Durability and Monopoly." Journal of Law and Economics 15 (1): 143-149.

Cohen, Gerald. 1995. Self-Ownership, Freedom, and Equality. Cambridge: Cambridge University Press.

Feser, Edward. 2005. "There is No Such Thing as an Unjust Initial Acquisition.” Social Philosophy and Policy 22 (1): 56-80.

Friedman, David. 1989. The Machinery of Freedom: Guide to a Radical Capitalism. Second edition. Chicago: Open Court Publishing. 
Gul, Faroukh, Hugo Sonnenschein, and Robert Wilson. 1986. "Foundations of Dynamic Monopoly and the Coase Conjecture." Journal of Economic Theory 39 (1): 155-190. Hart, Oliver, and Jean Tirole. 1988. "Contract Renegotiation and Coasian Dynamics." Review of Economic Studies 55 (4): 509-540.

Kant, Immanuel. 1996 [1797]. The Metaphysics of Morals. Edited by Mary Gregor. Cambridge: Cambridge University Press.

Kymlicka, Will. 1990. Contemporary Political Philosophy: An Introduction. Oxford: Oxford University Press.

Locke, John. 1967 [1689]. Two Treatises of Government. Edited by Peter Laslett. Second edition. Cambridge: Cambridge University Press.

North, Douglass C., Terry L. Anderson, and Peter J. Jill. 1983. Growth and Welfare in the American Past: A New Economic History. Third edition. Englewood Cliffs: Prentice-Hall.

Nozick, Robert. 1974. Anarchy, State and Utopia. New York: Basic Books.

Pufendorf, Samuel von. 2005 [1672]. Of The Law of Nature and Nations. Oxford: The Lawbook Exchange.

Sanders, John T. 1987. "Justice and the Initial Acquisition of Property." Harvard Journal of Law and Public Policy 10 (2): 367-399.

Simmons, John. 1992. The Lockean Theory of Rights. Princeton: Princeton University Press.

Tirole, Jean. 1988. The Theory of Industrial Organization. Cambridge, MA: MIT Press. Waldron, Jeremy. 1988. The Right to Private Property. Oxford: Clarendon Press.

Mats Ekman is a graduate student of Economics at the Hanken School of Economics in Helsinki, Finland.

Contact e-mail: <mats.ekman@hanken.fi> 